\title{
Expressions of HPV 16-E6 in esophageal carcinoma and its clinical significance
}

\author{
Xing Zhao ${ }^{1^{*}}$, Rajina Sahi ${ }^{2}$, Yu-Yang Zhao ${ }^{1}$, Jun Wang ${ }^{1}$, Chun- Hui Li ${ }^{1}$
}

${ }^{1}$ Affiliated Hospital of Chengde Medical College, Chengde 067000, Hebei Province, China, ${ }^{2}$ B. P. Koirala Memorial Cancer Hospital, Nepal.

\section{DOI Name}

http://dx.doi.org/10.3126/jaim.v4i2.16897

\section{Keywords}

Esophageal carcinoma, HPV 16-E6;

Immunohistochemistry

\section{Citation}

Xing Zhao, Rajina Sahi, Yu-Yang Zhao, Jun Wang, Chun-Hui Li. Expressions of HPV 16-E6 in esophhageal carcinoma and its clinical significance. Journal of Advances in Internal Medicine 2015;04(02):57-60.

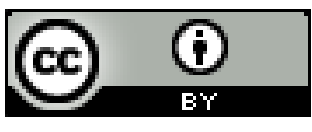

This work is licensed under a Creative Commons Attribution 3.0 Unported License.

\section{ABSTRACT}

Aim: The aim of the study was to explore the association between HPV16-E6 protein and esophageal squamous cell carcinoma.

Methods: SP immunohistochemical method was used to examine the expression of HPV 16-E6 in 50 cases of esophageal squamous cell carcinoma, 10 cases of normal esophageal squamous cell and 10 cases of adjacent tissue.

Result: The expressions of HPV 16-E6 was significantly higher in esophageal carcinoma than in normal esophageal mucosa and in adjacent tissue. The expressions of HPV 16-E6 had a significant correlation with invasive depth $(P<0.05)$, but not with the patient age, lymph node metastasis and tumor size $(P>0.05)$.

Conclusion: HPV 16-E6 can promote the growth and metastasis of esophageal squamous cell carcinoma and can be a prognostic factor of esophageal squamous cell carcinoma.

\section{INTRODUCTION}

Gastrointestinal cancer is the most common malignant tumor in China. In the recent years, the etiology and prognostic of gastrointestinal cancer have become gradually one of the modern medical research hot spots. This research aims at studying the etiology and prognosis of esophageal carcinoma. The role of high-risk human papilloma virus (HPV) was discussed in many other cancer research process. Studies showed that HPV had a coding region, including gene E1, E2, E4 , E5, E6 and E7 . Among them, E6 can activate the transcription of genes. Meanwhile, it can promote the proliferation of cells. ${ }^{[1,2]}$. There were also studies, showing that cervical diseases were relate to HPV16 E6 mRNA. ${ }^{[3,4]}$ The role of HPV in cervix cancer had been widely recognized. HPV18 and HPV16 may be pathogenic factors of mammary invasive ductal carcinomas, and the former may be also related to benign breast lesions. ${ }^{[5,6]}$ However, this study at home and abroad less the case with esophageal epithelial cells. Using immunohistochemical techniques, we aimed to study the expressions of HPV 16-E6 in normal esophageal mucosa, esophageal carcinoma and adjacent tissue, to explore its effect in esophageal epithelial cells infected with HPV, and to analyze the prognostic factor of esophageal squamous cell carcinoma.

\section{MATERIALS AND METHODS}

\section{Patients}

A total of 50 esophageal squamous cell carcinoma specimens, 10 normal esophageal mucosa specimens(negative resection margin) and 10 adjacent tissue specimens (a field that contains genetically abnormal cells, can be large $3 \mathrm{~cm}$ in diameter around the carcinoma ) underwent esophagectomy with lymph node dissection, at Affiliated Hospital of Chengde Medical College between the period from 2008 to 2011 were

\footnotetext{
* Corresponding author

Xing Zhao

Affiliated Hospital of Chengde Medical College,

Chengde 067000, Hebei Province, China,

E-mail:dczhaoxing@gmail.com
} 
included in this study, All specimens were formalin-fixed and paraffin embedded Neither of them undergo radiotherapy, chemotherapy and immunotherapy. Patient's gender, age, lymph node metastasis, tumor size and invasive depth are included in the study. The histologic subtypes of esophageal carcinoma were sub-classified by experience pathologic doctors.

\section{Immunohistochemistry}

All the esophageal tissue were fixed in $40 \mathrm{~g} / \mathrm{L}$ formaldehyde fixative and embedded in paraffin. Sections were dewaxed and rehydrated according to a standard procedure, incubated with $3 \mathrm{ml} / \mathrm{L}$ hydrogen peroxide in methanol for $15 \mathrm{~min}$ at room temperature. After washing twice with phosphate-buffered saline (PBS) for $5 \mathrm{~min}$, tissue sections were incubated at $37^{\circ} \mathrm{C}$ for 20 min with blocking solution. Sections were incubated at $37^{\circ} \mathrm{C}$ for 2 hours with primary antibody HPV 16-E6 (SC-584, Santa Cruz Biotechnology, Inc). After washing twice with PBS $(0.01 \mathrm{~mol} / \mathrm{L}, \mathrm{pH} 7.4)$ for $10 \mathrm{~min}$, tissue sections were incubated at $37^{\circ} \mathrm{C}$ for $30 \mathrm{~min}$ with biotin-anti-rabbit IgG. After washing twice with PBS for 5 min, tissue sections were incubated with streptavidin-HRP for $30 \mathrm{~min}$. Then the sections were washed twice in PBS, and they were incubated with metal-enhanced 3, 3-diaminobenzidene solution for $15 \mathrm{~min}$; then they were washed two times in distilled water and counterstained with hematoxylin. Negative control sections were incubated with PBS instead of primary antibody .The positive staining for HPV 16-E6 -synthesizing cells was expressed as red brown granules, which were mainly located in cell nucleus under microscopy. At least 5 high-power $\times 400$ fields were chosen randomly for cell counting. The ratio of the positive staining for HPV 16-E6-synthesizing cells were calculated by dividing the number of positive cells over the total number of cells. Tumors were then classified according to their expression of HPV 16-E6 upon overview of the section. The percentage of positive cells was divided into five grades (percentage cores): $\leq 5 \%=$ score $0 ; 6 \%-20 \%=$ score $1 ; 21 \%-50 \%$ = score $2 ; 51 \%-75 \%$ $=$ score 3 ; and $>75 \%=$ score 5 . HPV $16-$ E6 staining positivity was also determined by the scores: the scores $\leq 1$ was defined as negative, and $>1$ as positive.

\section{Statistical analysis}

The $\chi^{2}$ test was used to compare the relationship in frequency distributions between the expression of HPV 16-E6 and clinical indicators. The cut off value of statistically significance was defined as $p<0.05$. All the calculations were performed using SPSS18.0.

\section{RESULTS}

Expression of HPV16-E6 protein in esophageal carcinoma, adjacent tissue and normal esophageal squamous cell

The positive staining for HPV16-E6 -synthesizing cells were mainly located in cell nucleus under microscopy. Immunohistochemistry of different group showed that, of the 50 cases of esophageal squamous cell carcinoma, the rates of positive expression were $56 \%$. The rate of HPV16-E6 positive expression was lower in adjacent tissue and normal esophageal squamous cell $(50 \%, 30 \%)$ respectively than in esophageal squamous cell carcinoma. (Table 1).

Table 1. Expression of HPV16-E6 protein in esophageal carcinoma, adjacent tissue and normal esophageal squamous cell

\begin{tabular}{lccccc}
\hline \multicolumn{1}{c}{ Variables } & $\begin{array}{c}\text { Case } \\
\text { No. }\end{array}$ & positive & negative & $\boldsymbol{\chi}^{2}$ & $\mathbf{P}$ \\
\hline normal mucosa & 10 & 3 & 7 & $2.26^{\mathrm{a}}$ & $0.17^{\mathrm{a}}$ \\
adjacent tissue & 10 & 5 & 5 & $0.83^{\mathrm{b}}$ & $0.65^{\mathrm{b}}$ \\
esophageal carcinoma & 50 & 28 & 22 & $0.73^{\mathrm{c}}$ & $0.7^{4} \mathrm{c}$ \\
\hline Case No. & 440 & 200 & 240 & & \\
\hline
\end{tabular}

aesophageal carcinoma versus normal mucosa 'esophageal carcinoma versus adjacent tissue

${ }^{b}$ normal mucosa versus adjacent tissue

\section{Relationship of HPV16-E6 protein expression to clinicopathologic features}

Out of the 50 cases of esophageal squamous cell carcinoma, the expressions of HPV 16-E6 had been correlation invasive depth. $(P<0.05)$, but not with patient age, lymph node metastasis, tumor size and ( $>0.05)$. (Table 2). (Figure 1, Figure 2)

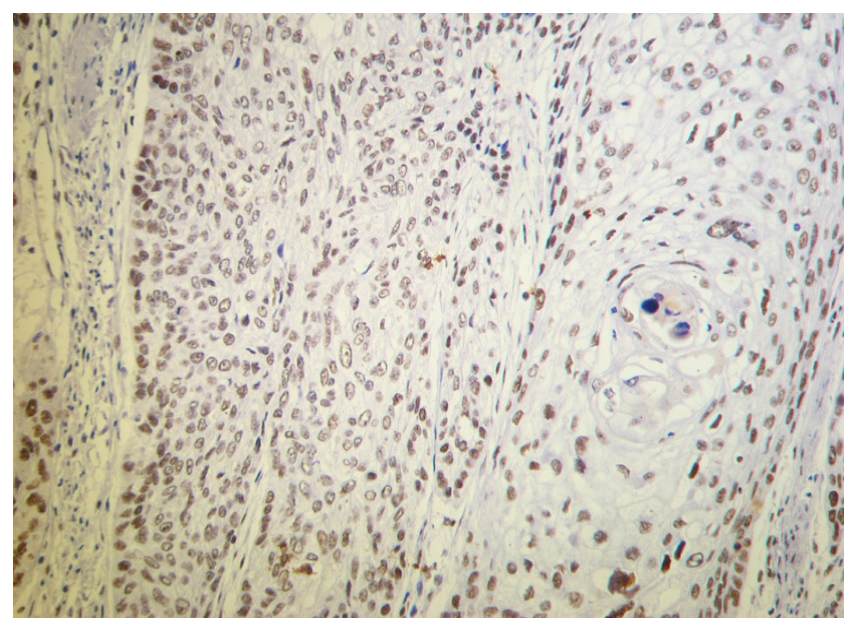

Fig.1 HPV16-E6 expression is more in cases with lymphatic metastasis SCC SP $\times 200$ 


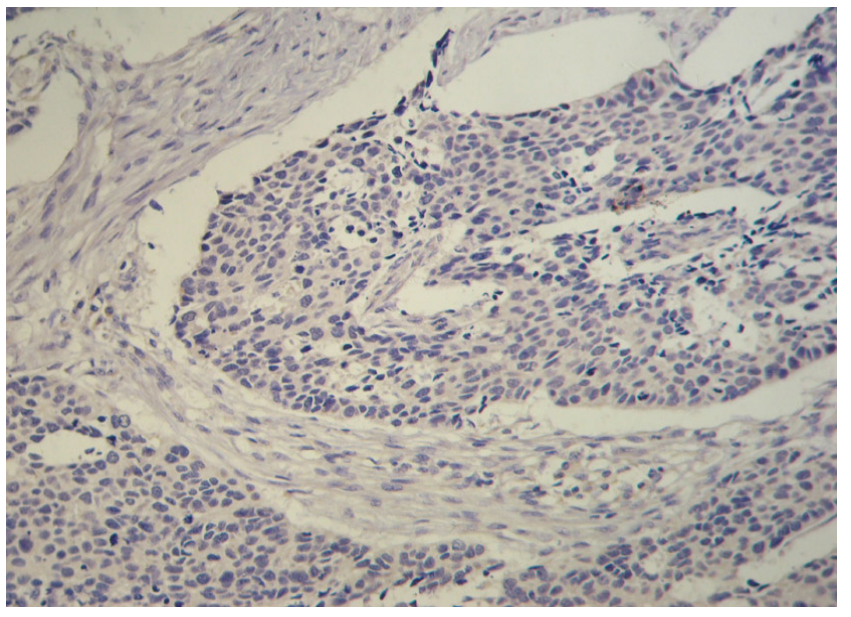

Fig.2 HPV16-E6 expression is less in cases without lymphatic metastasis SCC SP $\times 200$

Table 2. Relationship of HPV16-E6 protein expression to clinicopathologic features in 50 cases of esophageal squamous cell carcinoma

\begin{tabular}{|c|c|c|c|c|c|}
\hline & \multirow{2}{*}{$\begin{array}{c}\text { Case } \\
\text { No. }\end{array}$} & \multicolumn{2}{|c|}{$\begin{array}{l}\text { HPV16-E6 } \\
\text { expression }\end{array}$} & \multirow[t]{2}{*}{$\chi^{2}$} & \multirow{2}{*}{$\begin{array}{c}P \\
\text { value }\end{array}$} \\
\hline & & positive & negative & & \\
\hline \multicolumn{6}{|l|}{ Age(years) } \\
\hline$\leq 60$ & 23 & 14 & 9 & \multirow{2}{*}{0.41} & \multirow{2}{*}{0.58} \\
\hline$>60$ & 27 & 14 & 13 & & \\
\hline \multicolumn{6}{|l|}{ Tumor size(cm) } \\
\hline$<3$ & 18 & 7 & 11 & \multirow{3}{*}{4.09} & \multirow{3}{*}{0.13} \\
\hline $3 \sim 5$ & 23 & 14 & 9 & & \\
\hline$>5$ & 9 & 7 & 2 & & \\
\hline \multicolumn{6}{|l|}{ Invasion Depth } \\
\hline Mucosa submucosa & 5 & 0 & 5 & \multirow{3}{*}{65.71} & \multirow{3}{*}{0.02} \\
\hline Muscularis & 10 & 5 & 5 & & \\
\hline Outer membrane & 35 & 23 & 12 & & \\
\hline \multicolumn{6}{|c|}{ Lymph node metastasis } \\
\hline Positive & 22 & 14 & 8 & \multirow{2}{*}{0.93} & \multirow{2}{*}{0.39} \\
\hline Negative & 28 & 14 & 14 & & \\
\hline
\end{tabular}

\section{DISCUSSION}

Human papilloma virus is a group of DNA-containing viruses, notable for the double-stranded structures.Currently identified more than 100 types of HPV are described in detail. More than 70 types of HPV can infect a strictly defined type of epithelium and cause specific changes. There are many method to diagnose papillomavirus: for example, histological morphological examination, Immunohistochemistry and PCR .The most sensitive method currently recognized is the polymerase chain reaction (PCR) . The pathological criteria for diagnosis of HPV is koilocytic changes. The method have some advantages, page 59 for example convenience, with many disadvantages such as subjective and limitations. Immunohistochemistry allows the identification of capsid protein expression, which exist in a period of virus replication, and ending in false negatives. So immunohistochemistry is also not ideal. ${ }^{[7]}$ There were many reporting on the HPV, for example in cervix, urethra, pharynx, nasal cavity, oral cavity, bronchus and oesophagus. ${ }^{[8,9,10]}$ Recently, there were so much focus on the relationship of HPV and esophageal carcinoma ${ }^{[11,12]}$. It was reported that HPV-E6, E7 protein played a part in the occurrence and development of esophageal cancer. According to the carcinogenicity, HPV were divided into low and high risk groups. HPV16 was considered to be at high risk. Studies showed that HPV had a coding region, including gene E1, E2, E4, E5, E6 and E7. Among them, E6 can activate the transcription of genes and promote cell multiplication leading to runaway cell division and eventually tumor formation. Open reading frame encodes the protein of E6 and E7. The increased expression of E6 and E7 in cervical carcinoma are indispensable for maintaining the transition states of tumour cells ${ }^{[13,14]}$. Immunohistochemical method was used in this experiment to examine the expression of HPV 16E6 protein.

HPV 16-E6 protein contained 151 amino acids and 2 zinc finger. Its carcinogenesis is reflected as following: E6 protein expressed by high- risk- HPV16, 18 inhibit the action of P53 by accelerating degradation and inhibiting to enter its nucleus. On the other hand, HPV16-E6 plays an important role in the immortalization of normal cells induced by HPV16. The essential attribute of immortalization is the loss of control in the cell cycle regulation.

Li T et al ${ }^{[7]}$ have reported that loss of HPV 16-E6 protein expression is significantly associated with esophageal squamous cell carcinoma. They using PCR and ISH protocols reported that the prevalence of expression of HPV 16-E6 protein gene in the high incidence area was higher than that low incidence area. In addition, an association of HPV with esophageal carcinoma has been reported in China ${ }^{[15,16]}$. We used SP immunohistochemical method to examine the expression of HPV 16-E6 in 50 cases of esophageal squamous cell carcinoma, 10 cases of normal esophageal squamous cell and 10 cases of adjacent tissue and our analysis showed an association of HPV with esophageal cancer.

In conclusion, HPV 16-E6 can promote the growth and metastasis of esophageal squamous cell carcinoma and can be a prognostic factor of esophageal squamous cell carcinoma. 


\section{REFERENCES}

1 Paavonen J. Human papillomavirus infection and the development of cervical cancer and related genital neoplasias. International Journal of Infectious Diseases. 2007,11(2):S3 S9.

2 Agorators T, Dinas K, Lloveras B, et al. Cervical human papillomavirus infection in women attending gynaecological outpatient clinics in Northern Greece. European Journal of Cancer Prevention. 2004,13(2):145 147.

3 Lo KW, Wong YF, Chan MK, et al. Prevalence of human papillomavirus in cervical cancer: a multicenter study in China. International Journal of Cancer. 2002,100(3):327 331.

4 Sun ZR, Ji YH, Zhou WQ, et al. Characteristics of HPV prevalence among women in Liaoning province, China. International Journal of Gynecology and Obstetrics. 2010,109(2):105 109.

5 Sweewaldt VL, Mrozek K, Dietze EC, et al. Human papillomavirus type $16 \mathrm{E} 6$ inactivation of p53 in normal human mammary epithelial cells promotes tamoxifenmediated apoptosis. Cancer Research. 2001, 61:616.

6 Zhonghu He, Zhongyao Xu, Dong Hang,etal.AntiHPV-E7 seropositivity and risk of esophageal squamous cell carcinoma in a high-risk population in China.

Carcinogenesis. 2014,35(4):816 821.

7 Guo F, Liu Y, Wang X, et al. Human papillomavirus infection and esophageal squamous cell carcinoma: a case-control study. Cancer Epidemiol Biomarkers Prev, 2012, 21(5):780-5.

8 Klein F, Amin Kotb WF, Petersen I. Incidence of human papilloma virus in lung cancer. Lung Cancer $.2009,65(1): 13 \sim 18$.
9 Krishna SM, James S, Kattoor J, et al. Human papilloma virus infection in Indian nasopharyngeal carcinomas in relation to the histology of tumour. Indian Journal of Pathology and Microbiology. 2004,47(2):181 185.

10 Qi Z, Jiang Q, Yang J, et al. Human papillomavirus (HPV) infection and the risk of esophageal squamous cell carcinoma. Dis Esophagus, 2013,26(1):61-7.

11 Liyanage SS, Segelov E, Garland SM, et al. Role of human papillomaviruses in esophageal squamous cell carcinoma. Asia Pac J Clin Oncol, 2013 ,9(1):12-28.

12 Chang,F,Syrjanen,S,Shen, Q,Honxjiu,J.and Syrjanen, K Human papillomavirus(HPV)DNA in esophageal precancerous lesion and squamous cell carcinoma from China.Int.J.Cancer,1990,45(1),21-25.

13 Yugawa T,Kiyono T.Molecular mechanisms of cervical carcinogenesis by high-risk human papillomaviruses:novel functions of E6 and E7 oncoproteins. Reviews in Medical Virology. 2009,19(2):97 113.

14 A. Ravaggi, C. Romani, B. Pasinetti, R. A. Tassi,E. Bignotti,E. Bandiera, F. E. Odicino, M. Ragnoli, C. Donzelli,M. Falchetti, S. Calza, A. D. Santin, S. Pecorelli. Correlation between serological immune response analyzed by a new ELISA for HPV-16/18 E7 oncoprotein and clinical characteristics of cervical cancer patients. Archives of Virology, 2006,156(10) : 1899-1916.

15. Scuderi $P$, Jam es $R, H$ arris $L$, et al.Multimodal antiemetic management prevent $s$ early postoperative vomiting after outpatient laparoscopy. Anesth Analg, 2000, 91 (6) : 1408-1414.

16 Henzi I, Walder B, T t am er M R. Dexaethasone for the prevention of postoperative nausea and vomiting: a quantitative systematic review. Anesth Analg, 2000, 90 (1) : 186-194. 